\title{
ASSENTAMENTOS RURAIS NA METADE \\ SUL DO RIO GRANDE DO SUL E A SUA \\ COMPATIBILIDADE COM O BIOMA PAMPA: \\ ESTUDO NO ASSENTAMENTO SÃO JOAQUIM ${ }^{1}$
}

\author{
Nájila Souza da Rocha ${ }^{2}$ \\ Francis Casagranda Zanella ${ }^{3}$ \\ Jefferson Marçal da Rocha ${ }^{4}$ \\ Rafael Cabral Cruz ${ }^{5}$
}

Resumo: Neste trabalho analisam-se as práticas agrícolas desenvolvidas pelos agricultores assentados no Assentamento São Joaquim, localizado no município de Santana do Livramento, na chamada Metade Sul do Rio Grande do Sul (RS). Considera-se que a Metade Sul se caracteriza como uma região com altos índices de concentração fundiária e econômica desde sua formação. Esta região é coberta pelo bioma Pampa, cuja biodiversidade tem sido ameaçada por polêmicos projetos de desenvolvimento. Nesse contexto, analisam-se as repercussões do modelo de ocupação proposto pela política de assentamentos rurais na região desde a década de 1980 a partir das estratégias de uso e ocupação do solo colocadas em prática no São Joaquim. A coleta e análise de dados se deu através de uma triangulação dos seguintes métodos: geoprocessamento com imagens de satélite, observações in loco no assentamento e entrevistas com os assentados. A partir da análise dos dados, constatou-se que são ainda poucas as práticas sustentáveis utilizadas pelos agricultores assentados. Porém, a percepção de que as atuais práticas precisam mudar, para garantir a manutenção do bioma e da própria reprodução como agricultores familiares, pode ser um importante subsídio na implantação de políticas que incentivem um desenvolvimento rural sustentável.

\footnotetext{
${ }^{1}$ Apoio CNPq Universal 2013 e Fundação de Amparo à Pesquisa do Estado do Rio Grande do Sul (FAPERGS). ${ }^{2}$ Doutoranda em Sensoriamento Remoto na Universidade Federal do Rio Grande do Sul. E-mail: <najila.rocha2011@gmail.com>.

${ }^{3}$ Mestrando em Extensão Rural na Universidade Federal de Santa Maria. E-mail: <franciszanella@gmail.com>. ${ }^{4}$ Doutor em Meio Ambiente e Desenvolvimento. Professor na Universidade Federal do Pampa. E-mail: <jeffersonrocha@unipampa.edu.br>.

${ }^{5}$ Doutor em Ecologia. Professor na Universidade Federal do Pampa. E-mail: <rafaelcruz@unipampa.edu.br>.
} 
Palavras-chave: Sustentabilidade; Desenvolvimento rural; Bioma Pampa; Agricultura familiar; Reforma agrária.

Abstract: In this study we did an analysis of agricultural practices developed by farmers settled in the São Joaquim Settlement, located in Santana do Livramento, in the so-called southern half of Rio Grande do Sul (RS). It is considered that the southern half has been characterized as a region with high rates of land and economic concentration since its formation. This region is covered by the Pampa biome, whose biodiversity has been threatened by controversial development projects. In this context, we analyze the repercussions of the occupation model proposed by the rural settlements policy in the region since the 1980s, based on the land use and occupation strategies implemented in São Joaquim. Data collection and analysis was done through of a triangulation of the following methods: GIS with satellite images, observations in-loco in the settlement and interviews with farmers settled. From the analysis of the data, it was verified that there are still few sustainable practices used by settled farmers. However, the perception that current practices need to change to ensure the maintenance of the biome and its own reproduction as family farmers can be an important subsidy for the implementation of policies that encourage sustainable rural development.

Keywords: Sustainability; Rural development; Pampa biome; Family farming; Land reform.

\section{Introdução}

O Rio Grande do Sul (RS) apresenta em sua formação uma configuração territorial caracterizada por diferentes processos de ocupação promovidos desde o século XVIII em suas áreas de campos e de florestas (ZARTH, 2002). A denominada Metade Sul, predominantemente coberta por campos, se constituiu como um território demarcado pelo processo de ocupação portuguesa e espanhola no continente americano. Os latifúndios e a pecuária de baixa lotação foram a regra na sua formação econômica entre os séculos XVIII e XIX (PESAVENTO, 1985). Como resultado desse processo, se tem uma forte concentração fundiária e a dedicação quase que exclusiva à criação de gado pelas grandes propriedades denominadas estâncias. Já na parte Norte, especialmente nas predominantes áreas com cobertura original de florestas, o processo de colonização se intensificou a partir de meados do século XIX e se caracterizou pela formação de minifúndios ocupados por imigrantes europeus não ibéricos, que desenvolveram uma agricultura de base familiar (ZARTH, 2002). Para Rocha (2011) este processo de ocupação originou uma linha imaginária entre as partes Sul e Norte a partir do final do século XIX. Esta demarcação representa diferenças significativas em como se condicionou a configuração socioeconômica, política, cultural e ambiental de cada região.

A atividade pecuária em grandes propriedades foi capaz, por um lado, de conservar a biodiversidade deste bioma, mas não teve o mesmo sucesso nas dimensões social e econômica. A lógica produtiva das estâncias, baseadas em um manejo de baixa lotação das pastagens, levou a uma seleção natural da vegetação com base no pastoreio, no pisoteio e no fogo (CRUZ; GUADAGNIN, 2010). Este processo resultou em campos de alta diversidade, com representativas áreas prioritárias para conservação da biodiversidade, onde se apresentam cerca de 400 espécies de gramíneas, 150 de leguminosas e cerca de 3.000 espécies no total do bioma resultante (MMA, 2007). Para Cruz e Guadagnin (2010), essa lógica contribuiu para manter a biodiversidade peculiar do bioma Pampa, que se estende por toda a Metade Sul e, ainda, por parte da Argentina, Uruguai e Paraguai.

A característica de predomínio da atividade pecuária nas estâncias permaneceu dominante até o segundo terço do século $\mathrm{XX}$, quando lavouras de arroz e soja começaram a ser cultivadas com maior frequência na região, muitas por agricultores oriundos da região Norte do RS (PICCIN, 2012). A partir da década de 1980 se fortalece uma estagnação econômica na Metade Sul por conta da crise do modelo de produção pecuária nas estâncias (ROCHA, 2011). Assim, se intensificou um contexto histórico de desigualdade e concentração de bens e renda nas regiões demarcadas pelos domínios estancieiros. Em função do avanço da agricultura industrial, com maior intensidade nesse período, o processo de degradação e substituição da cobertura original do bioma é acelerado e, por isso, seu status de conservação atualmente é preocupante (MMA, 2007). Além disso, a emergência de grupos transnacionais da indústria papeleira, através do plantio de monocultivos de árvores nas décadas de 1990-2000, traz, enquanto proposta de desenvolvimento para a Metade Sul, fortes traços de modelo homogeneizador trazido de outros contextos, sem levar em conta as características culturais e os recursos naturais locais (BREITENBACH; BRANDÃO, 2014).

Nesse bojo, foi só a partir de 1980 que movimentos sociais do campo 
fortaleceram reivindicações para suprimir desigualdades sociais e fundiárias deste território. Além da estagnação econômica e formação latifundiária na Metade Sul, outro fator chave para as mobilizações por terras foi a necessidade de se encontrar colocação para a população rural excedente da região norte do RS (NAVARRO et al., 1999). Esse grupo vivenciava um processo de êxodo rural em função do esgotamento da fronteira agrícola no estado assim como pelas contradições resultantes da subordinação dos agricultores familiares ao capital agroindustrial (ALVES; SILVEIRA; FERREIRA, 2007; ANDREATTA et al., 2009). A política de assentamentos foi implantada a partir desse período por intermédio das pressões exercidas para desapropriações de terras em todo o estado, especialmente pelo Movimento dos Trabalhadores Rurais Sem Terra (MST).

Atualmente, no RS, estão assentadas aproximadamente 13.000 famílias, localizadas em 330 projetos de assentamento (INCRA, 2013). Rocha, Zanella e Cruz (2013) apontam que a lógica de produção adotada em parte dos lotes de beneficiários desses assentamentos rurais é considerada incompatível no contexto do bioma Pampa. Para os autores, um conjunto de motivos estruturais corrobora para esse cenário nos assentamentos: famílias camponesas oriundas do norte do RS e portadoras de conhecimentos sobre uma racionalidade produtiva não adaptada ao Pampa; lotes com não mais de 25 hectares, inviáveis economicamente para uma ocupação de baixa intensidade no contexto dos campos do bioma; limitações para aquisição de áreas pelo Instituto Nacional de Colonização e Reforma Agrária (INCRA); insuficiente planejamento no desenvolvimento dos assentamentos rurais; precariedade das políticas de extensão rural. Em outras palavras, há um conjunto de restrições que opera sobre a política de assentamentos rurais como um todo e que tende a limitar as margens de ação do Estado em termos de ajustamento da política às necessidades locais. Nesse sentido, o próprio entendimento de política de assentamentos está vinculado ao seu caráter pontual de operação, dependente das pressões de movimentos sociais contra estruturas conservadoras que permeiam a atuação do Estado (LEITE et al., 2004).

Dado o contexto territorial da Metade Sul e da política de assentamentos, sintetizado acima, o objetivo deste trabalho é analisar a dinâmica de uso e ocupação do solo a partir de imagens de satélite, de observações in loco e de entrevistas com agricultores assentados no Assentamento São Joaquim, em Santana do Livramento/RS. Procurou-se estudar, neste caso analisado, as repercussões do modelo de ocupação proposto pela política de assentamentos rurais em termos de compatibilidade com o bioma. Portanto, analisam-se possibilidades e limites para que o modelo de assentamentos rurais vigente se constitua em estratégia sustentável no contexto do território e bioma em que está inserido.

\section{Encaminhamentos metodológicos}

Para analisar a compatibilidade das estratégias desenvolvidas no PA São Joaquim, o trabalho baseou-se em uma triangulação de métodos: geoprocessamento, análises in loco e entrevistas com os agricultores assentados. Na interpretação dos dados obtidos sobre o assentamento foram apontadas, além da situação atual, algumas tendências possíveis e alternativas viáveis tendo como referência o desenvolvimento rural sustentável.

Considera-se como desenvolvimento rural sustentável a construção de estratégias e modelos de agricultura de base familiar capazes de contemplar, de forma integrada, as dimensões social, econômica, ambiental, política, cultural e ética (CAPORAL; COSTABEBER, 2002). Dessa forma, a sustentabilidade não pode ser entendida apenas de modo parcial, seja como justiça social ou conservação ambiental, mas sim em conjunto e em crescente emergência para níveis mais avançados. É nesse sentido amplo das dimensões da sustentabilidade que se compreendem, no contexto deste trabalho, os desafios para a consolidação dos assentamentos rurais no contexto da Metade Sul do RS e do bioma Pampa.

Em termos de etapas da construção deste estudo, foram utilizadas ferramentas do geoprocessamento em um primeiro momento. De acordo com Xavier da Silva (2001), o geoprocessamento focaliza, primordialmente, o levantamento e a análise de situações ambientais representadas por conjuntos de variáveis georreferenciadas e integradas em uma base de dados digital. Podese afirmar que a utilização do geoprocessamento nas pesquisas nos espaços agrários possibilita, a partir da análise, manipulação e cruzamentos de dados georreferenciados, estabelecer relações e correlações entre informações.

Tomadas essas considerações, foi elaborado o mapa atual de uso e cobertura do solo do assentamento, referente a março de 2013, a partir de imagens de satélite disponíveis no Google, com o uso do ArcGis 9.3. Procurou-se manter os mesmos símbolos, cores e classificação propostos pelo INCRA em seu relatório no ano de 2005, para fins de comparação, o qual classificou o assentamento em áreas de: Agricultura/Solo Exposto; Pousio; Campo úmido; Campo Seco; Mata e Silvicultura, além de áreas alagadas (Água). Porém, 
para uma análise capaz de contemplar todas as categorias identificadas no mapa atual, foi necessário incluir as classes: Capões/Vegetação Alta e Sede (local de moradia dos agricultores). Consideraram-se "Capões/ Vegetação Alta" como as áreas com vegetação alta, normalmente exótica, mas sem as características da classe "Silvicultura" ou "Mata". São áreas de vegetação alta próximas às moradias, ou partes isoladas em meio ao campo.

Para subsidiar e confirmar as informações obtidas foram feitas observações in loco sobre uso e cobertura do solo, em outubro do mesmo ano. As observações, feitas por pesquisadores do grupo, foram realizadas em pontos aleatórios do assentamento, considerando as diferentes classes de uso e cobertura do solo identificadas. Estas observações tinham um alcance visual de, em média, 150 metros de raio. As informações obtidas em cada ponto foram armazenadas em gravador digital de áudio. Foram marcados os pontos no Global Posiction System (GPS) e obtidas fotos, que serviram para uma análise das variáveis verificadas no georeferenciamento. O uso de binóculos também foi feito, apenas para confirmar algumas observações. Em laboratório, as observações dos pontos foram plotadas no mapa de uso e cobertura do solo.

O procedimento adotado resultou no que se denominou 'Zonas de Conflito'. São resultado das comparações entre o observado in loco e o que foi classificado por meio das imagens de satélite, cruzado com as informações sobre aptidão das áreas. Além de confirmar as classificações, a partir das observações foi possível caracterizar melhor o uso da terra, suas depreciações e pressões sofridas, que podem vir a diminuir a qualidade ambiental do local. Com esses resultados foi possível também apontar possíveis consequências, em curto prazo, do uso e cobertura do solo identificados.

Um segundo momento deste estudo foi demarcado pela pesquisa de campo. Foram realizadas entrevistas com membros adultos de 20 diferentes famílias assentadas (de um total de 37 no assentamento), escolhidas de forma aleatória no mês de outubro de 2013. Apesar da aleatoriedade dos entrevistados, levou-se em conta diferentes áreas do assentamento (tipo de relevo, vegetação predominante no lote e distância do acesso principal, entre outras) e diferentes formas de localização das suas residências (no lote e na agrovila) $O$ principal objetivo foi entender o modo de vida dos assentados, suas percepções quanto ao uso da terra e os recursos naturais no assentamento, além das perspectivas de desenvolvimento em suas práticas e de permanência das famílias.

Na realização das entrevistas, a ideia principal era de que o pesquisador seguisse o participante. Sendo assim, as discussões das respostas são de cunho subjetivo e empíricas, importantes para a complexidade da compreensão de questões sociais, econômicas e ambientais (MINAYO, 2000). As análises foram feitas a partir da Teoria das Representações Sociais (MOSCOVICI, 2010), e as interpretações a partir de uma avaliação integrada entre discursos e práticas na dinâmica do uso e cobertura do solo no assentamento São Joaquim.

Em termos de localização do assentamento estudado, vale destacar que se localiza no município de Santana do Livramento, RS, cujo qual conta com outros 30 Projetos de assentamentos (PAs) em seu território. O PA São Joaquim, analisado nesse trabalho, localiza-se nesse município, na área de abrangência da Bacia Hidrográfica do Rio Santa Maria, às margens da rodovia BR 158, e tem o Rio Ibicuí como seu principal afluente (Figura 1). Foi implantado no ano de 1996 em uma área de 1044,10 hectares, com capacidade de assentar 37 famílias em lotes de 28,22 hectares em média. A área dos lotes é dividida em uma parte produtiva e uma área de preservação. Nesta última foram realocados 4 hectares de cada lote para a mata ciliar do rio, e são consideradas reserva legal do assentamento (COPTEC, 2009).

Figura 1 - Localização da área de estudo

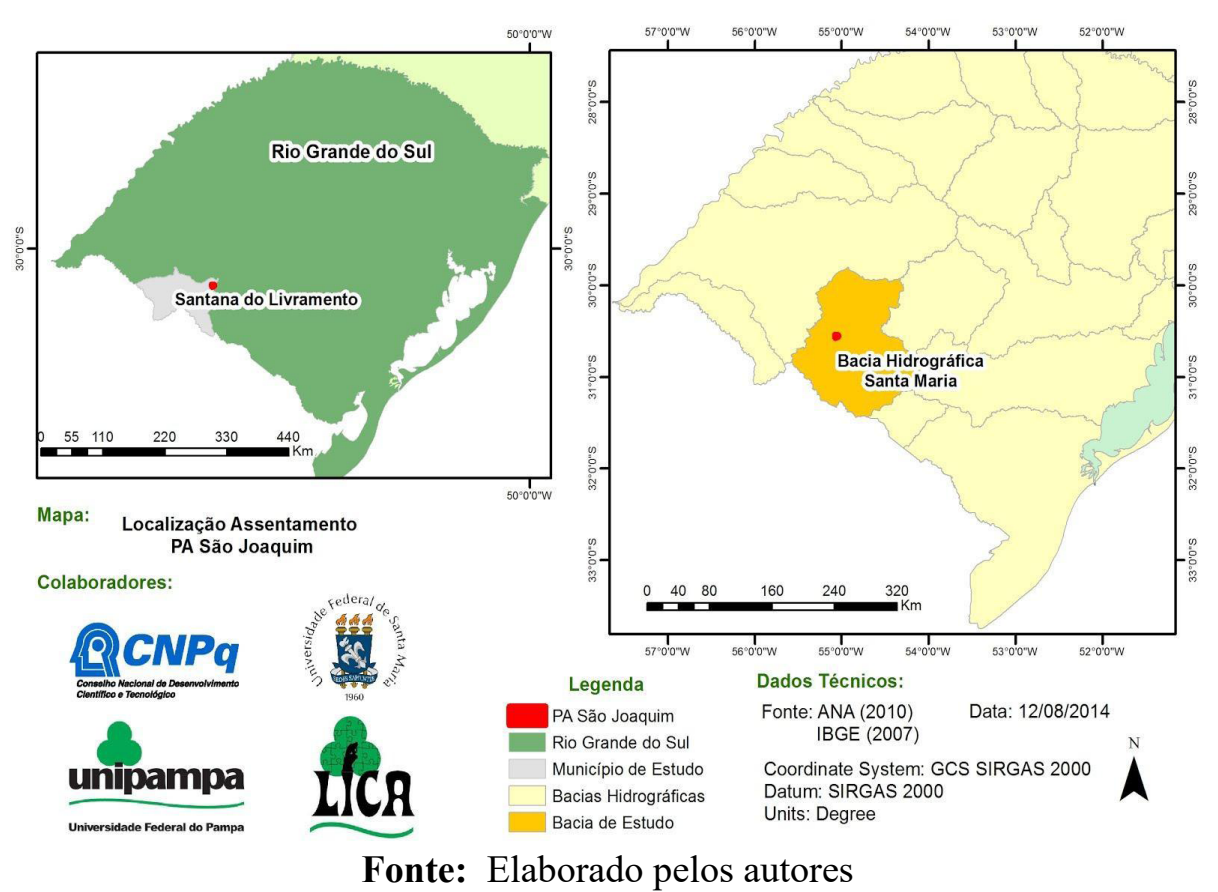

v. 20, n.1, $2017 \quad$ RETRATOS DE ASSENTAMENTOS 


\section{Resultados e discussões: tendências do uso e cobertura do solo}

Quanto à análise do uso e cobertura do solo, através de imagens de satélite referentes ao ano de 2013 (Figura 2), a presença significativa de áreas com cobertura campestre demonstra uma tendência de mudança nos sistemas produtivos dos assentamentos da região, com uma dedicação maior à produção de leite (ROCHA et al., 2014). Entretanto, boa parte das manchas apresenta cultivos anuais, principalmente no plantio de milho e de pastagens, para alimentação do rebanho bovino, e de soja para comercialização do grão.

Figura 2 - Mapa de uso e cobertura do solo no assentamento São Joaquim em 2013



Fonte: Elaborado pelos autores

Na comparação com os dados do INCRA (2005), referentes a 2003, os resultados atuais sobre manchas apontam para uma maior fragmentação (de 57 para 123) e diversidade (nova categoria capões/vegetação alta). Percebe-se também que o aumento na quantidade de manchas em áreas de agricultura e campo seco, ao contrário do ocorrido em áreas úmidas, representa a priorização de áreas secas para cultivos de grãos e pastagens, um uso mais fragmentado. $\mathrm{O}$ aumento na quantidade de capões/vegetação alta e de reservatórios de água (açudes) está associado aos ativos das famílias na adaptação aos lotes e, também, a elementos ligados à atividade leiteira.

Por suas condições edafoclimáticas ${ }^{6}$, todo o assentamento, conforme estudo do INCRA (2005), é adaptado para uso apenas ocasional com culturas anuais, alternadas com culturas semipermanentes, e para uso temporário com culturas de verão adaptadas, inclusive com arroz irrigado. Conforme o estudo há limitações quanto à produção agrícola, pois é grande o risco de erosão do solo se utilizado continuamente com lavouras anuais. Apenas espécies de ciclos produtivos longos, de 3 a 4 anos, são recomendados. As áreas mais próximas das margens do rio são inaptas para qualquer cultivo, com risco de erosão até com a cobertura original de campo ou floresta.

\section{Lógicas de ocupação dos lotes e o processo de adaptação ao assentamento}

A partir dos resultados das entrevistas realizadas constatou-se que a região de origem das famílias do assentamento é a Metade Norte do RS, todas da área rural de diferentes municípios. Essa tendência de assentados oriundos da região norte do estado reforça a análise de que as pressões pela reforma agrária na Metade Sul se deram sobremaneira por agricultores atingidos por processos de êxodo rural a partir da década de 1970 (ANDREATTA et al., 2009; ALVES; SILVEIRA; FERREIRA, 2007).

Além disso, ao considerar o modo de vida e costumes dessas famílias, na luta pela terra e retomada de condições para sua reprodução socioeconômica com qualidade de vida, apresentam-se características de uma agricultura familiar camponesa. Esta presa, em primeira instância, pelo crescente alcance de condições de vida (PLOEG, 2008), diferente da lógica empresarial, em expansão no bioma Pampa, que visa principalmente o lucro através do incremento em escala (ROCHA, 2011).

Consequentemente, o fato de que a maioria dos agricultores assentados expressam determinada origem regional (norte do RS), acarreta em ações e percepções sobre as diferentes condições sociais e ambientais encontradas

${ }^{6}$ Quanto aos solos do assentamento, são predominantemente Argissolos vermelhos, que em partes são distróficos abrúpticos e em outras distróficos arênicos, ou ainda eutróficos arênicos. Também ocorrem Planossolos eutróficos e distróficos, e em partes hidromórficos. Em $86 \%$ da área do assentamento a declividade está entre 00 e $05 \%$, e em 12,8\% entre $05 \%$ e $10 \%$ (COPTEC, 2009 apud MDA/INCRA, 2009). 
na Metade Sul, no contraste entre uso da terra, concentração fundiária, características edafoclimáticas, questões sociopolíticas e culturais. A declaração a seguir de um agricultor assentado, dada em entrevista, expressa essa sensação de estranhamento no aspecto climático e produtivo:

No início a gente sofreu muito pra acostumar, aqui é diferente o clima com o do norte, até as plantas, a gente chegou aqui e começou plantar como plantava lá e não deu certo, acabamos perdendo muita coisa em muitos anos, plantamos muito cedo e aqui demora mais esquentar e tudo. No início foi sofrido, 2 a 3 anos, depois pegou o ritmo da região, conversando com pessoas daqui foi pegando.

A partir deste breve relato pode-se perceber que ao longo do tempo se sucedeu uma série de mudanças na tentativa de adaptação dos assentados ao contexto da região, ou seja, de "pegar o ritmo". Nos primeiros anos a atividade agrícola foi voltada ao plantio de grãos e de alimentos para subsistência, muito do que já se fazia na região norte e que se tentou reproduzir no assentamento. Porém, esta estratégia não se mostrou adaptada às limitações edáficas e climáticas, e muitos assentados contraíram dívidas nesse período, devido aos insucessos das colheitas. As principais dificuldades foram percebidas na medida em que se tentava manter os antigos costumes e modo de vida na nova realidade. Nesse processo, a transição entre desterritorialização e reterritorialização leva a mudanças e permanências, à (des) continuidades no processo de adaptação, onde alguns elementos permanecem e outros são substituídos (SAQUET, 2006).

É nesse sentido que uma estratégia melhor adaptada se fortaleceu na tentativa de amenizar os riscos da dependência dos plantios anuais. $\mathrm{O}$ manejo de vacas para produção de leite, associado ao plantio de milho para alimentação dos animais, além da produção diversificada para subsistência, se tornou o principal sistema produtivo do assentamento. No momento da pesquisa, 17 famílias (85\%) aplicavam esta prática, de diferentes formas em termos de estrutura e manejo. Apesar de variações na quantidade de leite produzida e no preço pago ao longo do ano, o leite é considerado uma fonte de renda segura e mensal para sobrevivência. Com essa renda são pagas as contas, as compras mensais e são supridas emergências, o que garante uma maior estabilidade nas relações econômicas. Esta prática faz parte do conjunto de atividades realizadas na origem das famílias, que foi potencializada, em detrimento de outras, por sua melhor adaptação.

Este posicionamento demonstra a busca de autonomia para sobrevivência, a partir do distanciamento de modelos altamente dependentes da instabilidade no mercado concorrencial capitalista e, ainda, de condições climáticas favoráveis. Isso se deu tanto pela capacidade de percepção dessas debilidades e na busca de soluções, como também pelo alcance de maior valor agregado na produção de leite, obtido através do reforço de uma base local de recursos (PLOEG, 2008). Estes dois posicionamentos são mencionados como estratégicos para reduzir as relações de dependência.

A produção de leite se estabilizou no assentamento pela adaptação (ainda que parcial) às limitações do lote e de necessidades das famílias. Parcial, pois apesar de depender menos de variações do mercado e do clima, ainda não o faz de uma forma compatível com as aptidões edáficas, ou seja, os cultivos tanto de grãos como da maioria das pastagens são anuais, e, frequentemente com revolvimento do solo, como foi analisado com dados empíricos.

\section{Zonas de Conflito: uma análise da compatibilidade das práticas agrícolas}

Por meio das observações de pesquisadores em diferentes pontos do assentamento foram definidas zonas representativas de conflitos quanto às práticas de uso e cobertura do solo frente à sua aptidão. Construíram-se mapas de cada uma destas zonas e anexaram-se fotos obtidas nos pontos observados in loco, de modo que se elaboraram as figuras que seguem nos parágrafos seguintes.

A partir da análise da Figura 3, sobre o uso e cobertura do solo em 2013, percebe-se que em maio desse ano a área em vermelho era coberta por agricultura/solo exposto, e a área em verde claro, por campo seco. Na verificação in loco, os pontos observados (fotos inseridas na Figura 3) foram classificados pelos pesquisadores como "Pastagem Cultivada/ Solo Exposto". As diferenças constatadas, principalmente se analisado apenas o campo seco (classificado nas imagens de satélite) podem ser explicadas pela época de coleta das imagens. Tal diferença demonstra a dinâmica do uso e cobertura em diferentes épocas do ano.

O conflito identificado nas observações e entrevistas se dá no uso intensivo de minérios e adubos inorgânicos pelos agricultores assentados para aumento da fertilidade do solo (Foto do ponto 190). Ainda, observando 
Figura 03 - Pastagens Cultivadas/Solo Exposto



Fonte: Elaborado pelos autores

esses pontos, foi possível identificar que o uso de maquinários pesados vem aumentando o desgaste da terra que visivelmente não é adequada para esse tipo de produção. Solos rasos, com camadas arenosas somando mais de um metro de profundidade foram observados nesses pontos (Foto do ponto 191 A). O manejo de gado leiteiro é praticado em ampla maioria com pastagens cultivadas em manejo convencional do solo e com uma alta quantidade de animais por hectare. A produção de milho e de soja é praticada ora em plantio direto ora em convencional, mas sempre anual e acompanhado do pacote agroquímico de fertilizantes e agrotóxicos. Devido à limitação do tamanho do lote no contexto da necessidade de renda para reprodução socioeconômica, foi relatado que não é aplicada a prática de rotação de culturas com áreas de pousio, pois seria uma redução significativa na renda deixar de utilizar uma parte do lote a cada ano.

Neste modelo produtivo, com tal intensidade, aliada à solos frágeis e de baixa fertilidade, não se apresenta alternativa para os agricultores se não a de utilizar recursos exógenos em grande quantidade. Em relação a esta incompatibilidade, os agricultores, em entrevista, reconhecem as principais limitações ligadas a estes sistemas de produção, como no caso que se apresenta a seguir:

[...] enfraquece rápido essa terra, de um ano pro outro dá diferença, cai lá em baixo a produção. A gente busca sempre manter cobertura e coisa assim pra não dar erosão. Por enquanto está se mantendo, desde que chegamos. Pra frente aí depende de nós.

Nesse contexto, os agricultores percebem que "enfraquece rápido a terra", no sentido de que a reposição de fertilidade e as práticas conservacionistas tendem a ser contínuas para manter os níveis de produção tidos como necessários. Evidenciam a centralidade de suas práticas como responsáveis pelas condições de ir "se mantendo", num entrelaçamento contraditório entre as necessidades imediatas de produção e consumo com as condições de reprodução futuras.

Na Figura 4 são apresentados dois pontos que se destacaram nas observações, por estarem em uma área de vale, ao sul do assentamento, próximo a áreas úmidas e de baixa exploração.

Nestas áreas, há presença de material erosionado (Fotos do ponto 197), que ao longo do tempo se deposita e forma áreas extensas com acúmulo de areia. Esse material é carregado por gravidade e pelo vento, das áreas acima, que são manejadas de forma intensiva com uso de maquinários pesados.

Considera-se ainda que, como consequência disto, além de provocar o alto grau de instabilidade deste ambiente, acarreta na perda de áreas nativas que poderiam servir de aporte para vegetação e fauna do local, na conservação do bioma Pampa.

$\mathrm{Na}$ Figura 5, podem-se observar pontos em que os agricultores procuram manter habitats que, em primeira instância, cumprem função de quebra-vento e sombreamento. São úteis tanto para a produção leiteira como para melhores condições de vida, por meio do incremento de qualidade nos arredores das habitações. Isto, por consequência, também representa novos nichos ecológicos, em áreas como quintais, pomares e manchas arborizadas. Representa manutenção da vegetação local quando há associações com campo nativo.

Entretanto, áreas com campo nativo são isoladas e pouco frequentes em todo o assentamento, o que pode demonstrar que esses agricultores não reconhecem nos campos o potencial para produção bovina. Tal produção 
Figura 04 - Campo Nativo com material erosionado
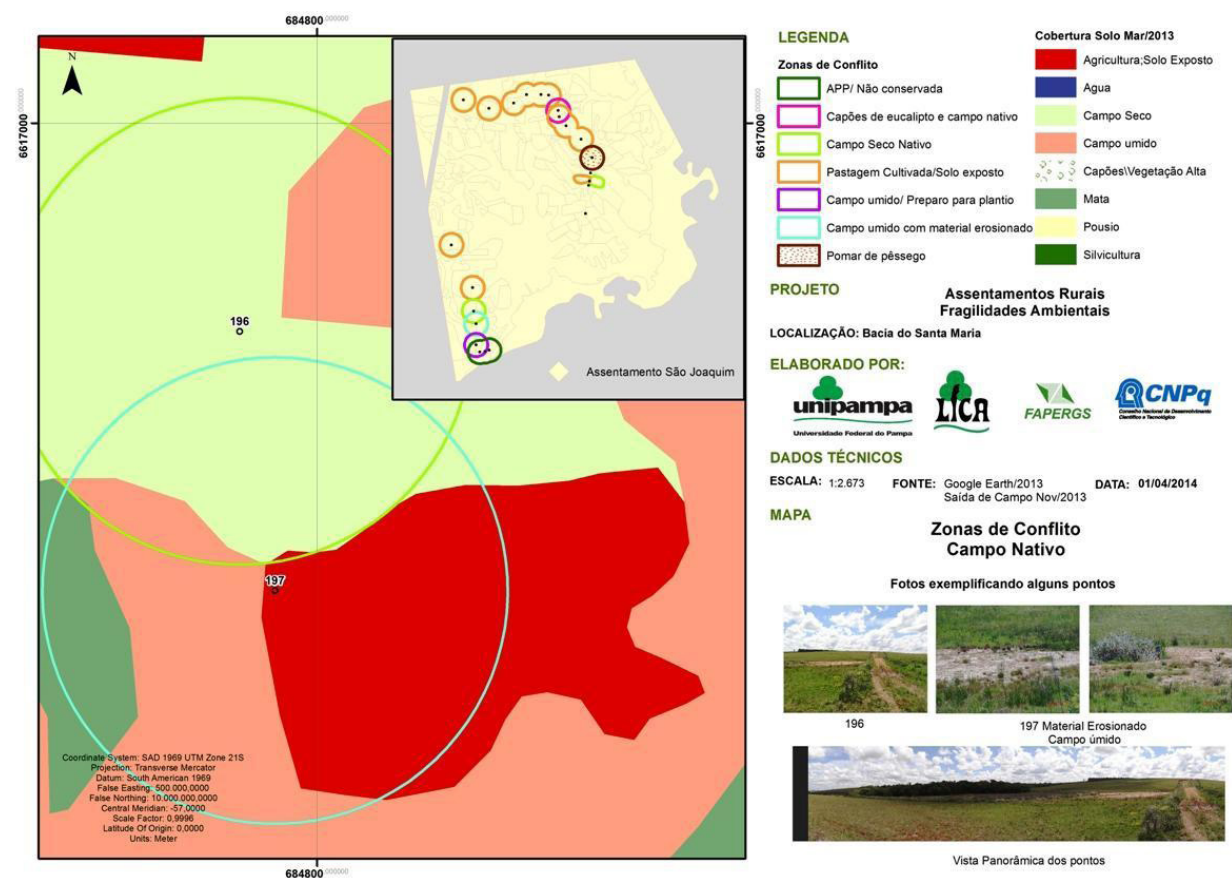

Fonte: Elaborado pelos autores

representa o modo tradicional de uso sustentável para conservação do bioma Pampa (OVERBECK et al., 2009).

Quanto às representações e significados referentes à paisagem pampeana, os assentados foram questionados sobre o que viam quando chegaram à área que se tornou assentamento. Algumas expressões são comuns quando se faz menção aos campos, e geralmente denotam um senso comum que atribui sentido improdutivo ao lugar, que a seu ver se tornou produtivo com a inserção dos cultivos e demais instalações e moradias. Seguem algumas declarações recorrentes registradas em entrevista com agricultores assentados:

Tudo que tem aqui a gente fez, era campo nativo, bruto, plantamos árvores, tudo né.

Era só campo, capinzal, muito alto, não tinha nada, nem árvore, nem nada, foi tudo nós que plantamos.

Percebe-se, portanto, um olhar que admite a introdução de árvores e cultivos como relativa a uma reconversão produtiva das áreas que, na



Fonte: Elaborado pelos autores

percepção dos que chegavam, "não tinha nada". Essa lógica também reflete a ideologia dos movimentos de luta pela terra que identificam nos campos naturais um dos símbolos do latifúndio improdutivo. Além disso, representa a cultura camponesa na região norte do RS, onde os cultivos agrícolas compõem a subsistência e fontes de renda. Por sua trajetória de vida desconhecem as possibilidades de uso produtivo e sustentável do campo nativo.

Quanto às áreas de preservação permanente na Figura 6, foram observadas algumas inconformidades com relação à legislação. Os três pontos observados, localizados às margens do rio que passa ao lado do assentamento, foram considerados 'não-preservadas', pois há vestígios de que o rebanho bovino chega às margens do rio de forma aleatória e sem um manejo adequado.

Apesar disso, há indícios da presença de animais campestres rastejantes, mamíferos de pequeno porte e aves da fauna nativa. Seria necessária uma melhor análise desta área para que se possa confirmar degradação de zonas ripárias. Porém, como há presença de dejetos de animais domésticos, além de trilhas formadas por gado e seres humanos, comprova-se a existência de nível considerável de impacto no uso destas áreas. 
Figura 06 - Áreas de Preservação Permanente (não conservada) e Campo Úmido

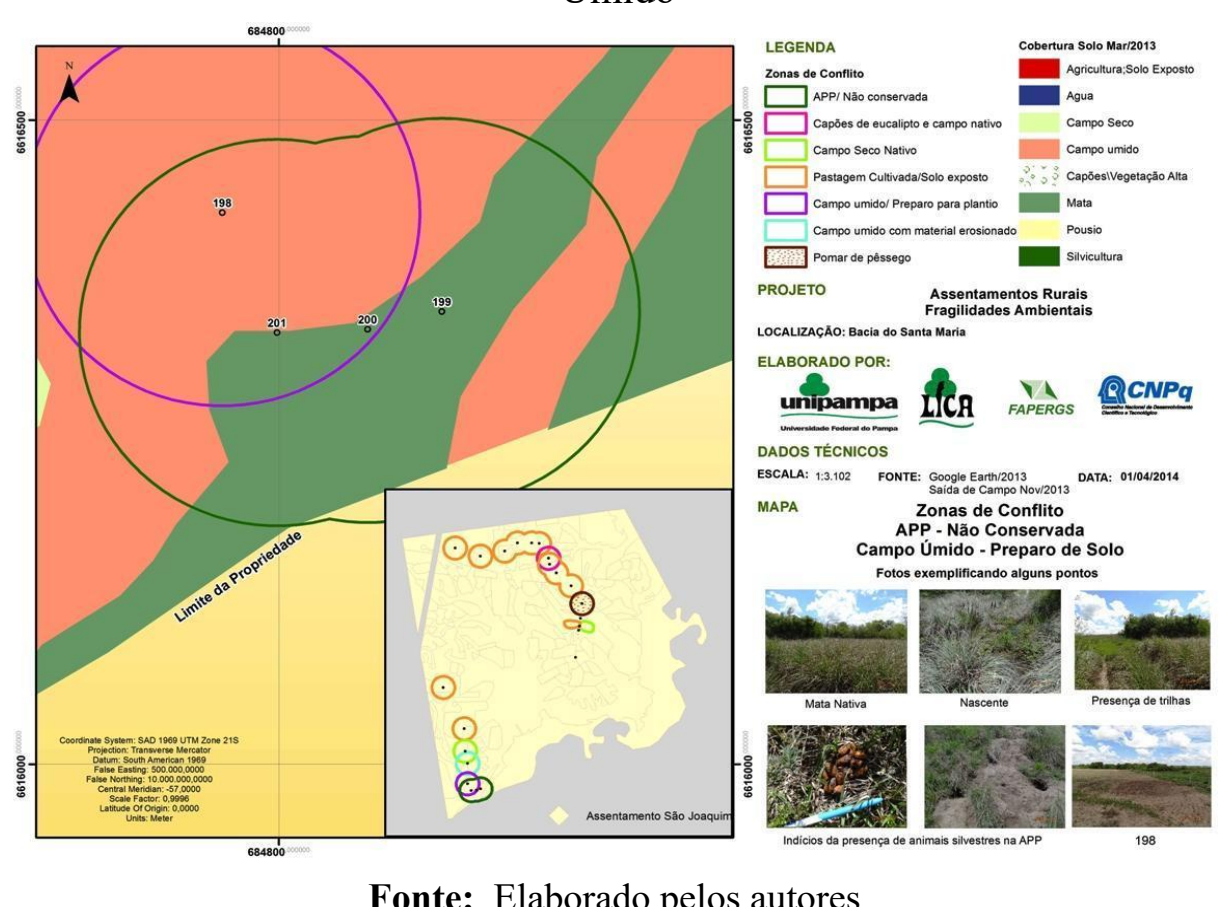

Fonte: Elaborado pelos autores

\section{Tendências e possibilidades para o desenvolvimento rural sustentável}

Ao tomar o conjunto de conflitos identificados, com representativa área e impactos negativos, estes representam desafios tanto do ponto de vista econômico, como social e ambiental para o desenvolvimento do assentamento. Sob o ponto de vista da sustentabilidade, os resultados apresentados demonstram obstáculos inerentes ao processo de consolidação do assentamento. Há um alcance incompleto das dimensões de um desenvolvimento rural sustentável, mas em processo de melhoria em relação a fases anteriores da formação do assentamento.

Para uma perspectiva durável da produção leiteira em gradual aumento de autonomia, agregação de valor e conservação do bioma, os agricultores assentados necessitam reduzir consideravelmente a dependência de modelos exógenos de pecuária familiar e de produção de grãos. A partir da transição agroecológica é necessário incorporar as potencialidades naturais locais do bioma aliadas ao desenvolvimento. Nesse sentido, o contexto de restrições da aptidão de uso das terras, principalmente em fragilidade e baixa fertilidade, pode deixar de ser considerado o principal limitante. Isso dependerá das estratégias adotadas.

Uma delas é o manejo coerente da biodiversidade local por intermédio de uma pecuária que potencialize a possibilidade de valorização do esforço pela conservação. É nesse sentido que uma alternativa viável de renda não-agrícola para diminuir as pressões do uso e cobertura do solo, seria o pagamento por serviços ambientais (PSA). Entre outras vantagens, essa alternativa, além de conservar o bioma, tenderia a diminuir o êxodo rural dos jovens, manter a produtividade do solo, diminuir o uso de agrotóxicos e ainda preservar os recursos hídricos. Estudos sobre este potencial no RS ainda são poucos (DELEVATI et al., 2013), mas intuitivamente se pode perceber uma potencialidade concreta de melhoria de qualidade de vida, aliada a preservação dos recursos naturais.

As dificuldades mais significativas para o desenvolvimento do assentamento, que têm influência sobre a sustentabilidade e alcance de autonomia, estão ligadas ao restrito tamanho dos lotes, às práticas de manejo prejudiciais à manutenção dos recursos naturais e à incerteza de sucessão familiar. Considerando estas restrições, projetam-se sinteticamente três possíveis cenários para o futuro dos assentados no PA São Joaquim, em tendências que podem ocorrer simultaneamente: a) tendência empresarial, resultando em contínua degradação dos recursos naturais locais, dependência de modelos exógenos e falta de condições para manutenção dos jovens; b) tendência camponesa, com incremento e intensificação de práticas conservacionistas, uso das potencialidades dos recursos locais e políticas públicas para consolidação do assentamento; e c) tendência de estagnação, através da manutenção de políticas mitigatórias para auxiliar a manutenção de famílias com condições básicas para sobrevivência, em baixos níveis de desenvolvimento.

\section{Considerações finais}

Por intermédio de uma triangulação de métodos procurou-se analisar, neste trabalho, as possibilidades e limitações do modelo de assentamentos rurais proposto para a região Metade Sul do RS. Para isso, levou-se em conta as estratégias produtivas tomadas no desenvolvimento do assentamento São Joaquim, em Santana do Livramento/RS. Deve-se levar em conta as limitações em termos de abrangência deste estudo de caso e, ao mesmo 
tempo, suas potencialidades para pensar os processos mais gerais que envolvem mudanças na cobertura do bioma Pampa.

A partir da análise dos dados georreferenciados, das observações in loco e das entrevistas realizadas, pode-se constatar que as estratégias adotadas pelos agricultores se configuram, de um modo geral, em duas categorias: uma é empresarial, na lógica de produção agrícola baseada em uso de agroquímicos e ligadas a mercados específicos do agronegócio, em especial na produção de soja; a outra ligada a uma concepção camponesa de produção, está basicamente ligada à produção leiteira, na redução do uso de insumos agroquímicos e na busca por melhores condições de vida. Nas escolhas cotidianas das famílias, verificou-se que estas estratégias não ocorrem tão separadamente, visto que a própria produção de leite empregada envolve certos graus de dependência de recursos externos.

$\mathrm{Na}$ dimensão ambiental pode-se considerar que o uso do pacote agroquímico e a inadequação do manejo do gado leiteiro tem provocado o surgimento de algumas áreas propensas à erosão e degradação do solo. Os resultados indicam ainda que neste assentamento ocorreu substituição da vegetação original do bioma Pampa por cultivos agrícolas. Nesse sentido, há um forte indício de que a origem cultural das famílias assentadas, oriundas da região norte do RS, levou-as a desenvolver cultivos agrícolas não totalmente adequados a aspectos edafoclimáticos do bioma Pampa, o que causou perdas agrícolas e financeiras, além de certo grau de degradação ambiental.

Pode-se então sintetizar, pelos resultados obtidos, que as estratégias agrícolas utilizadas pela maioria dos agricultores assentados no PA São Joaquim são insustentáveis, pois o modelo produtivo se mostrou intensivo e incompatível. Ao mesmo tempo em que parte das estratégias familiares envereda por lógicas camponesas de busca da autonomia (PLOEG, 2008), o alcance amplo das dimensões da sustentabilidade (CAPORAL; COSTABEBER, 2002) ainda é limitado.

É necessário ter em conta a presença de preocupação no discurso de muitos assentados quanto às restrições dos cultivos anuais, o que ocorre na medida em que se dá a transição para a produção de leite. A percepção de que o atual tipo de manejo é prejudicial à manutenção de sua atividade agrícola no futuro pode ser um importante aliado na transição para práticas conservacionistas. Para isto se concretizar, é preciso que as políticas públicas se voltem efetivamente no incentivo a práticas sustentáveis e endógenas de agricultura, em especial em biomas pouco conservados e estudados, como o bioma Pampa.

\section{Referências Bibliográficas}

ALVES, F. D.; SILVEIRA, V. C. P; FERREIRA, E. R. Territorialização camponesa, identidade e reproduções sociais: os assentamentos rurais na metade sul do Rio Grande do Sul. CAMPO-TERRITÓRIO: revista de geografia agrária, Uberlândia, v. 2, n.4, p. 82-97, ago. 2007.

ANDREATTA, T. et al. Origens da formação agrária sul rio-grandense no contexto brasileiro. In: $47^{\circ}$ Congresso da Sociedade Brasileira de Economia e Sociologia Rural (SOBER), 2009, Porto Alegre-RS. Anais... Porto AlegreRS: UFRGS, 2009. v. CD-ROM.

BREITENBACH, R.; BRANDÃO, J. B. Florestas de eucaliptos na Fronteira Oeste do Rio Grande do Sul: promessas e evidências. REDES, Santa Cruz do Sul, v. 19, n. 1, p. 216-235, jan./abr. 2014.

COPTEC. Cooperativa de Prestação de Serviços Técnicos Ltda. PRA: Plano de Recuperação do Assentamento São Joaquim. Santana do Livramento-RS: COPTEC/MDA/INCRA, 2009. 126 p. Disponível em: $<$ http://coptec.org/index.php/nucleos-operacionais/category/30-santanado-livramento?download=214:pa-so-joaquim> . Acesso em: 06 abr. 2017.

CAPORAL, F. R., COSTABEBER, J. A. Análise multidimensional da sustentabilidade: uma proposta metodológica a partir da agroecologia. Agroecologia e desenvolvimento rural sustentável, Porto Alegre, v. 3, n. 3, 2002.

CRUZ, R. C.; GUADAGNIN, D. L. Uma pequena história ambiental do Pampa: proposta de uma abordagem baseada na relação entre perturbação e mudança. In: COSTA, B. P.; DIECKEL, M. E. G. (Org.). A sustentabilidade da Região da Campanha-RS: Práticas e teorias a respeito das relações entre ambiente, sociedade, cultura e políticas públicas. Santa Maria-RS: UFSM, PPG Geografia e Geociências, Dep. de Geociências, 2010, v. 1, p. 155-179. DELEVATI, D. M.; KLEINERT, T. R.; TONIN, T. L.; RABUSKE, A. C. 
Projeto de pagamento por serviços ambientais (PSA) na sub-bacia do arroio Andréas - bacia hidrográfica do rio Pardo - RS - Brasil. In: XX Simpósio Brasileiro de Recursos Hídricos, Bento Gonçalves, 2013. Anais... Bento Gonçalves: ABRH, 2013. Disponível em: <http://www.abrh. org.br/SGCv3/UserFiles/Sumarios/da49e818e580e0a2bc327bde 752f110f_3577ed3660afa58d00033ff836054eca.pdf > . Acesso em:06 abr. 2017.

INCRA. Instituto de Colonização e Reforma Agrária. Relatório Ambiental do Projeto de Assentamento São Joaquim (Nova Santa Rita) Santana do Livramento/RS. Porto Alegre: INCRA, 2005. 60 p. Disponível em: $<$ http://coptec.org/index.php/nucleos-operacionais/category/30-santanado-livramento?download=214:pa-so-joaquim > . Acesso em: 06 abr. 2017.

INCRA. Instituto Nacional de Colonização e Reforma Agrária. Superintendência 11/RS. Relatório de Gestão do Exercício de 2012. Porto Alegre-RS. Disponível em: <http://www.incra.gov.br/sites/default/files/ uploads/servicos/publicacoes/relatorios/relatorios-de-gestaao/2012/relatorio_gestao_sr11_rs.pdf $>$. Acesso em: 06 abr. 2017.

LEITE, Sérgio Pereira et. al., (Coord.) Impactos dos assentamentos: um estudo sobre o meio rural brasileiro. São Paulo: Editora Unesp, 2004.

MINAYO, M. C. S. Ciência, técnica e arte: o desafio da pesquisa social. In: MINAYO, M. C. S. (Org.) Pesquisa social: teoria, método e criatividade. Petrópolis-RJ: Editora Vozes, 17 ed., 2000. p. 9-30.

MMA. Ministério do Meio Ambiente. Áreas Prioritárias para Conservação, Uso Sustentável e Repartição de Benefícios da Biodiversidade Brasileira: Atualização - Portaria MMA nº, de 23 de janeiro de 2007. Brasília: MMA, 2007. 300 p

MOSCOVICI, S. Representações Sociais: Investigações em Psicologia Social. Trad. Pedrinho A. Guareschi. 7 ed. Petrópolis: Vozes, 2010. 408 p. NAVARRO, Z.; MORAES, M. S.; MENEZES, R. Pequena história dos assentamentos rurais no Rio Grande do Sul: formação e desenvolvimento. In: MEDEIROS, L. S.; LEITE, S. (Orgs.) A formação de assentamen- tos rurais no Brasil: processos sociais e políticas públicas. Porto Alegre: EDUFRGS, 1999. p. 19-68.

OVERBECK, G. E. et al. Os Campos Sulinos: um bioma negligenciado. In: PILLAR, V. P. et al. (Orgs.) Campos Sulinos: Conservação e Uso Sustentável da Biodiversidade. Brasília-DF: Ministério do Meio Ambiente, 2009, v.1, p. $175-198$

PESAVENTO, S. História da Indústria Sul-rio-grandense. Guaiba-RS: Riocell, 1985.

PLOEG, J. D. van der. Camponeses e Impérios Alimentares: lutas por autonomia e sustentabilidade na era da globalização. Tradução de Rita Pereira. Porto Alegre: Editora da UFRGS, 2008. 372 p.

PICCIN, M. B. Os Senhores da Terra e da Guerra no Rio Grande do Sul: um estudo sobre as práticas de reprodução social do patronato rural estancieiro. 2012. 457 f. Tese (Doutorado em Ciências Sociais) - Universidade Estadual de Campinas, Campinas. 2012.

ROCHA, J. M. As Raízes da Crise da Metade Sul: Estudo da formação econômica do Rio Grande do Sul. Jaguarão-RS: UNIPAMPA, 2011. 192 p

ROCHA, J. M.; ZANELLA, F. C.; CRUZ, R. C. Reforma agrária no Bioma Pampa: aspectos para repensar os métodos de desapropriação e distribuição de terras na Metade Sul do RS. Cadernos de Agroecologia, v. 8, n. 2, nov. 2013. Disponível em: <http://www.aba-agroecologia.org.br/revistas/index.php/cad/article/view/15065/9136> . Acesso em: 06 abr. 2017.

ROCHA, J. M. et al. Uso do geoprocessamento para análise temporal de uso da terra no Assentamento São Joaquim. In: $4^{\circ}$ Seminário Brasileiro de Gestão Ambiental na Agropecuária, Bento Gonçalves, 2014. Anais... Bento Gonçalves: Embrapa Uva e Vinho, 2014, p. 158-163.

SAQUET, M. A. CAMPO-TERRITÓRIO: considerações teórico-metodológicas. CAMPO-TERRITÓRIO: Revista de Geografia Agrária, Uber- 
lândia, v. 1, n. 1, fev. 2006. p. 60-81.

XAVIER-DA-SILVA, J. Geoprocessamento para análise ambiental. 1. ed. Rio de Janeiro: D5 Produção Gráfica, 2001. v. 1. 228 p.

ZARTH, Paulo Afonso. Do arcaico ao moderno: o Rio Grande do Sul agrário do século XIX. Ijuí-RS: Ed. Unijuí, 2002. 320 p. 